\title{
ПРОБЛЕМА КОММУНИКАЦИИ В СОВРЕМЕННОМ ОБЩЕСТВЕ И ПУТИ ЕЕ РЕШЕНИЯ В СВЕТЕ ТЕОРИИ КОММУНИКАТИВНОГО ДЕЙСТВИЯ Ю. ХАБЕРМАСА
}

\section{И.А. Яременко}

Актуальность данной статьи обусловлена тем, что в современном глобализирующемся обществе проблема коммуникации имеет первостепенное значение. Об интересе исследователей к проблеме интерсубъективного общения свидетельствуют многочисленные труды, относящиеся к различным аспектам научного знания. Эта проблема рассматривается представителями разных научных школ с точки зрения семиотики, герменевтики, лингвистики, психологии, психолингвистики, прагматики, социологии и т. д. В ее исследовании использовались самые разнообразные методы и подходы. Проблемами коммуникации занимались такие выдающиеся философы как Ф.Ницше, Т. Адорно, Л. Витгенштейн, Х.-Г. Гадамер, К. Ясперс, Ч. Пирс, К.-О. Апель, Ю. Хабермас и др. Среди современных русских и украинских исследователей можно назвать В. Табачковского, Р. Цаголову, С. Барматову, Т. Дридзе, Е. Андроса, В. Ситниченко, А. Назарчука, Л. Савину и др. Но несмотря на разные методы и подходы, общей чертой современных исследований является мысль о том, что коммуникация в современном обществе представляет собой сложный механизм, который «обеспечивает социальность как таковую и социальное воспроизводство как таковое, она цементирует общество» [2, с.90]. Поэтому исследование этого механизма, определение закономерностей и противоречий

Актуальні проблеми духовності 
его развития и основных «рычагов» управления им выступает основной задачей философии и других наук на современном этапе.

Одним из исследователей, которые первыми осознали эту проблему, является немецкий философ Ю. Хабермас. В своей работе «Теория и практика» он пишет, что «философия вступила сегодня в такую стадию исследования, когда необходима коллективная организация прогресса в философии, это значит, в форме междисциплинарного проекта, в котором ни философия, ни другие отдельные науки не будут занимать привилегированное положение по отношению друг к другу» [13, с. 16]. Анализируя социальные процессы как процессы коммуникации, он разработал свою теорию коммуникативного действия в качестве широкомасштабной теории общества. Поэтому изучение трудов этого философа в рамках исследования феномена коммуникации является вполне логичным.

Термин «коммуникация» (лат. «соmmunicatio»-связываю, делаю общим) появляется в научной философской литературе в начале 20-го века. По определению А.В. Назарчука, «в понятии коммуникации речь идет в первую очередь об обмене между субъектами коммуникации информацией различного рода» [5, с. 220]. Иными словами, коммуникация - это процесс общения, в котором участвуют как минимум два субъекта, процесс, основным содержанием которого является «духовное общение, благодаря которому человек не превращается из субъекта в объект массового влияния» [6, с. 23]. Коммуникация-это общение, в процессе которого человек не играет роли, предложенные ему обществом, а «раскрывает себя как актер, самостоятельно исполняющий все роли» $[6$, с. 23$]$.

В настоящее время этот термин интерпретируется как: а) средство связи любых объектов материального и духовного мира; б) общение передача информации от человека к человеку; в) передача и обмен информацией в обществе с целью воздействия на него. Для понимания понятия «коммуникация» важны все три толкования термина. Первое связано с проблемами дифференциации и систематизации коммуникативных средств, которые различны по своей природе, структуре, функциям и эффективности; второе - с проблемами межличностной коммуникации; третье - с проблемами массовой коммуникации. Коммуникация выступает посредником между индивидуальной и общественно осознанной информацией. По мнению Р.С. Цаголовой, «ключевой проблемой коммуникации является механизм, который переводит индивидуальный процесс передачи и восприятия информации в социально значимый процесс персонального и массового воздействия. 
Этот механизм заложен в речевой деятельности людей - именно в ней реализуются социально обусловленные нормы и правила общения» $[9$, c. 85]. Она подчеркивает, что коммуникация самым непосредственным и тесным образом связана с реальной жизнью людей в социуме, что вся картина их жизнедеятельности и функционирования общества как целостного организма отражена и закреплена в коммуникации. Одним из важных проявлений коммуникации исследовательница считает социальную коммуникацию, под которой понимается коммуникативная деятельность людей, обусловленная целым рядом факторов - социологических, психологических, этнокультурологических и социолингвистических. Социальная коммуникация - это «социально обусловленный процесс в условиях межличностного и массового общения, в рамках которого формируются индивидуальные и групповые коммуникативные установки, реализация которых происходит в конкретных социальных условиях при помощи коммуникативных средств (вербальных и невербальных)» $[9$, с. 86$]$. По мнению Р.С.Цаголовой, понятие коммуникации определяется совокупностью понятий социологического, социопсихологического и коммуникативного содержания:

1. Социологические понятия: социальные структуры общества, общественные отношения, социальная ситуация и группы, социальный стереотип, социальные ценности, условия, традиции и т. д.

2. Социопсихологические понятия: межличностные отношения, социальная роль, коммуникативная компетентность, общая историческая память, речевое взаимодействие, социальный конфликт и кооперация как формы речевого взаимодействия, моральнонравственные ценности и др.

3. Коммуникативные понятия: коммуникативная сфера, коммуникативный контекст и коды, языковые средства общения, коммуникативные роли, межличностная, межгрупповая и массовая коммуникация, коммуникативная личность и т.д.

О значении коммуникации в жизни человека говорит и Евгений Андрос, который исследует коммуникацию на фоне ее проблемных срезов, внутренне связанных между собой - соотношении монологичности и диалогичности человеческого общества. Опираясь на исследования М. Бубера и подчеркивая, что человеческая жизнь принципиально коммуникативна, он выделяет в коммуникации два вида отношений человека к миру: «Я-Оно» и «Я-Ты». При этом речь идет не только 
о двух формах коммуникации, но и о двух определяющих измерениях человеческого существования. И именно через коммуникативное измерение можно прийти к пониманию как целостного человеческого существования, так и сущности познания, к пониманию истины.

Первая форма коммуникации «Я-Оно» монологична по своей природе. Это-мир внешних для нас вещей (когнитивно-прагматичный мир). «В системе только такого общения человек становится вещью среди вещей и не может вырваться за рамки своих ролевых функций. Это та сфера, которая направлена на отделение и отчуждение человека от других людей, она обособляет, искривляет и замыкает на себе человеческое существование и человеческое естество» [1, с. 227]. Однако человеческая жизнь по своей природе не такова, она многомерна, объемна, неоднозначна. Поэтому, в случае сведения всех коммуникативных отношений лишь к отношению «Я-Оно», можно говорить об утилитарной форме общения, монологичном мире, которые ведут к расцвету индивидуализма как общественного явления. Этой форме коммуникации соответствует «инструментальное» или «стратегическое» действие Ю. Хабермаса, превращающее субъектов в средства для достижения целей отдельных индивидуумов. Инструментальным действиям Ю.Хабермас противопоставляет коммуникативные действия, которые соответствуют отношениям «Я-Ты» в типологии М.Бубера и, в дальнейшем, Е.Андроса. Эти отношения представляют собой «диалогическую коммуникативную связь, которая определяет не только сферу непосредственной речевой коммуникации, но и всю совокупность межчеловеческих взаимоотношений, т. е. сферу интерсубъективного на всех уровнях: межиндивидуальном, культурном, социальном, межэтническом и правовом» $[1$, с. 228$]$.

Именно благодаря диалогу как реализации полноценных межчеловеческих отношений развивается один из наиважнейших механизмов построения цивилизованной жизни современного человека и осуществляется на практике процесс устранения отчуждения в современном обществе, что рассматривается Ю. Хабермасом как одна из важнейших задач современной философии.

Деление коммуникации на два стиля - монолог и диалог - характерно и для теоретических исследований Н.А. Колотиловой, которая отмечает, что для философии ХХ века характерно повышенное внимание к процессам коммуникации между людьми. «Монолог - это такой тип общения, в котором один субъект представляет истинное знание, до которого он либо дошел сам вследствие внутреннего диалога, либо получил из каких-то первоисточников аподиктическим путем. При 
этом субъект уверен, что представляет истину в последней инстанции» [4, с.33]. Диалог, по ее мнению, это тип общения, в котором принимают участие как минимум два субъекта. Она делит диалоги на две разновидности - диалектический и интерсубъективый. В первом случае субъекты равноправны и совместно ищут истину в реальной беседе путем ответа на вопросы. Характерной чертой такого диалога является то, что у собеседников нет сомнения относительно того, что истина существует, ее просто нужно найти. Интерсубъективный диалог - это разновидность диалога, в котором субъекты тоже равноправны, но, в отличие от диалектического, они не только ищут истину; это может быть общение по любому поводу. Характерной чертой такого диалога является то, что собеседники не знают, есть ли истина вообще. По мнению исследовательницы, монолог и диалектический диалог характерны для коммуникации в эпоху модерна, тогда как интерсубъективный диалог - это достижение философии постмодерна. Он «отказывается от любых гранднаративов, так как все наративы имеют одинаковое право на существование и нет оснований для определения какого-либо из них главным» [4, с. 34]. Философия интерсубъективности заменяет философию субъективности, которая по своей сути является монологичной и господствует в эпоху модерна. Философия интерсубъективности отказывается от фундаменталистских притязаний, но продолжает разрабатывать теорию рациональности. Она находит свое выражение в коммуникативной философии Ю. Хабермаса, которая противостоит постмодернистскому иррационализму как отказу от поиска истины. Хотя Ю. Хабермас признает, что никто не владеет истиной как таковой, но каждый человек может проблематизировать любое утверждение и пытаться обосновать свои высказывания, которые претендуют на истинность или значимость. По мнению Хабермаса, такие претензии могут быть признаны обоснованными посредством консенсуса, который достигается в дискурсе. «Именно в дискурсе мы пытаемся путем обоснований возобновить согласие, которое стало проблематичным в коммуникативном действии» $[8$, с. 84$]$.

В современной лингвистической литературе существует мнение, что термин «дискурс» начал активно употребляться в начале 70-х годов XIX столетия. В начале он использовался как синоним письменной или устной речи. И лишь позднее осознали, что дискурс-это более широкое понятие. Элементами дискурса являются определенные действия, их участники, информация и обстоятельства действий, на фоне которых они разворачиваются, оценка участников действий, а также информация, которая соотносит дискурс с действиями. «Дискурс- 
это своеобразная «речь в речи», которая представлена как особая социальная данность. Дискурс существует в текстах и посредством текстов. Однако это тексты особого рода, тексты, за которыми стоят особые грамматика, лексика, семантика, правила словообразования и синтаксис. В конечном итоге за такими текстами стоит особый мифологический мир. В мире дискурса действуют свои правила, ему присущи существенные представления об истине. Каждый дискурс-это один из возможных альтернативных миров» [3, с. 387].

По мнению В.Н.Фурса, понятие дискурса обладает продуктивной размытостью и не может быть подвергнуто однозначному определению. В общем плане оно обозначает относительно крупные единицы связной речи, рассматриваемые в экстралингвистическом контексте. Понятие дискурса позволяет тематизировать не только речь как таковую, но и разнообразные формы социальных практик, опосредованных речью. «Дискурс предстает, во-первых, как рациональная процедура аргументации, позволяющая посредством аппеляции к парадигмальной для данного сообщества очевидности достигнуть обоснованного и публично признанного согласия в отношении любых частных (исходящих от партнеров по коммуникации) претензий на значимость. Вовторых, подчеркивается креативность дискурса: консенсус не находится, а производится в процессе активного взаимного согласования позиций» $[7$, с. 32]. Особый интерес представляет попытка Ю. Хабермаса не только определить, но и установить взаимоотношения между такими понятиями как «дискурс» и «диалог». В своих трудах Ю. Хабермас не только дает определение этих понятий, но и обосновывает различия между «дискурсом» и «коммуникативным действием» как двумя формами коммуникации. В статье «Коммуникативное действие и дискурс» он описывает понятие коммуникации, включая в него не только речевые выражения, но и действия, поступки, переживания и их проявления. При взаимодействии людей речевые выражения и их неречевые проявления всегда связаны между собой. Коммуникативное действие может осуществляться между людьми во время их взаимодействия и без использования речи. Однако даже во время их речевого общения не всегда происходит коммуникативное действие. Таким образом, если коммуникативное действие не может считаться коммуникативным без учета внеречевого контекста, то в дискурсе следует обращать внимание лишь на речевые высказывания; поступки и состояния участников дискурса не являются его составными частями. В рамках коммуникативного действия «наивно, некритично допускают значения и смыслы с целью обмена информацией (необходимым для действия опытом); в 
рамках дискурса темой становятся проблематичные претензии на значимость и никакого обмена информацией не происходит» [8, с. 95]. Как полагает Ю. Хабермас, именно в дискурсе осуществляется попытка путем обоснования заново добиться соглашения, которое стало проблематичным в коммуникативном действии. В данном случае речь идет о дискурсивном взаимопонимании. Иными словами, конечной целью дискурса является достижение консенсуса в коммуникативном сообществе. Однако для того, чтобы консенсус был достигнут, необходимо выполнение условий дискурса всеми его участниками.

Прежде чем сформулировать условия или правила дискурса, Хaбермас предлагает различение аргументации на трех уровнях: условия логического уровня продукта, условия диалектического уровня процедуры и условия риторического уровня процесса. В качестве логико-семантического уровня он приводит следующие правила: «1.1. Ни один из говорящих не должен противоречить сам себе; 1.2. Каждый говорящий, который применяет предикат F к предмету а, должен быть готов применить этот предикат к другому предмету, схожему с а во всех отношениях; 1.3. Говорящие не должны использовать одно и то же выражение в различных значениях» [12, с. 97]. На этом уровне предпочтение отдается логическим и семантическим правилам, не имеющим этического содержания.

На процедурном уровне аргументация проявляется в качестве процессов взаимопонимания, которые регулируются таким образом, что пропоненты и оппоненты могут гипотетически проверить ставшие проблематичными претензии на значимость. К этому уровню относятся прагматические предпосылки специальной формы интеракции, необходимые для совместного поиска истины, например, признание компетентности и искренности всех участников. В качестве примера условий процедурного уровня Хабермас называет следующие правила: «2.1. Каждый говорящий должен утверждать только то, во что он верит сам; 2.2. Тот, кто использует высказывание или норму, не являющуюся предметом дискуссии, должен привести для этого убедительное основание» $[12$, с. 98]. Некоторые из этих правил имеют явное этическое содержание, например, отношения взаимного признания. Однако ни на логико-семантическом, ни на процедурном уровнях нельзя говорить о коммуникативном процессе: первый уровень - это логико-семантические условия аргументации, второй-прагматические. И лишь на риторическом уровне процесса аргументативная речь представляет собой коммуникативный процесс. «В аргументативной речи содержатся структуры речевой ситуации, которая особым образом защищена от 
репрессий и неравноправия: она представляет собой наиболее приближенную к идеальным условиям форму коммуникации» [12, с.98].

Развивая понятие «идеальные условия коммуникации», Хабермас предлагает следующие правила дискурса: «(3.1.) Каждый говорящий и действующий субъект имеет право принимать участие в дискурсе; (3.2.) а. Каждый имеет право проблематизировать любое утверждение; (3.2.) б. Каждый имеет право вводить в дискурс любое утверждение; (3.2.) в. Каждый имеет право выражать свое мнение, желания и потребности; (3.3.) Ни один из говорящих не должен подвергаться господствующему внутри или вне дискурса давлению в процессе использования своих прав, изложенных в пунктах (3.1.) и (3.2.)» $[12$, c.99]. Иными словами, правило (3.1.) определяет круг потенциальных участников, включая всех коммуникативно компетентных субъектов. Правило (3.2.) гарантирует всем участникам равные шансы в аргументации. Правило (3.3) гарантирует условия коммуникации: как право на универсальный доступ к дискурсу, так и право на равноправное участие в дискурсе.

Разрабатывая понятие дискурса и его основные правила, Хабермас стремится показать, что понимание, которое должно сложиться в ситуации, не предзадано и не запрограммировано заранее, оно не осуществляется автоматически. Для обозначения процесса достижения консенсуса Хабермас различает ряд дискурсов: теоретический дискурс, который осуществляется на основе когнитивных и инструментальных механизмов; практический дискурс, который связан с морально-практическими полаганиями и опирается на определение правильности и нормы действий; эстетический дискурс в форме эстетической критики, который строится на основе соотнесенности с ценностными стандартами; дискурс в форме терапевтической критики, характеристикой которого является выразительность, правдоподобность выражения; дискурс самовыражения и самообъяснения, который достигается выражением понятности того, что высказывается, и основывается на правильности формирования символических структур [11, с. 447-448].

В своей статье «Коммуникативное действие и дискурс» Хабермас предлагает следующую тематическую классификацию дискурсов: «а) дискурс как способ коммуникативного действия (напр., разговор с целью информации или организованный диспут); б) коммуникативное действие, которое лишь имеет форму дискурса (все формы идеологического убеждения); в) терапевтический дискурс, где создание условий для дискурса происходит на основе саморефлексии (психоаналитическая беседа между врачом и пациентом); г) нормальный дискурс, ко- 
торый служит для обоснования проблематичных претензий на значимость (напр., научная дискуссия); д) новые формы дискурса (обучение при помощи дискурса вместо обучения как способа передачи инструкций, Гумбольдтская модель свободной семинарской дискуссии)» $[12$, c. 85].

Таким образом, проведенный анализ показывает, что, хотя проблема интерактивного общения в коммуникативном сообществе занимала и продолжает занимать умы многих исследователей, первым ученым, который применил комплексный подход в решении этой проблемы, был Ю. Хабермас. Для современного общества с его усложнившимися коммуникативными структурами и интеграционными процессами необходима новая теория, которая не только отражает эти процессы и описывает проблемы, но и предлагает возможные пути их решения. Именно такую теорию и пытается создать Ю. Хабермас, разрабатывая свою концепцию коммуникативного действия. Его важнейшими достижениями в создании такой теории является, во-первых, выделение коммуникативного действия как наиболее значимой формы человеческого общения и, во-вторых, признание консенсуса конечной целью любого дискурса, который является высшей ступенью коммуникативного действия. Важным шагом в разработке действительно прогрессивной и продуктивной теории общества выступает то, что Хабермас не только дает определение понятия дискурса, но и формулирует основные условия и правила проведения дискурса и достижения консенсуса, что является необходимым в современном обществе, в котором, с одной стороны, идут процессы глобализации, а, с другой стороны, развиваются процессы отчуждения и враждебности. Как писал К.Богнер, один из исследователей философского учения Ю. Хабермаса, «характерной чертой его философии является то, что ... Хабермас не останавливается на анализе тенденций развития современного общества, он пытается также найти путь, по которому можно и следует идти» [10, c. 11].

\section{1 Литература}

[1] Андрос E. Метафізична та постметафізична доба у європейській гуманістиці // Філософія: світ людини. Курс лекцій. - Київ: Либідь, 2003.

[2] Дридзе T.M. Социальная коммуникация и фундаментальная социология на рубеже XXI века // Вестн. Моск. ун-та. Сер. 18. Co- 
циология и политология. - 1999. - № 4 .

[3] Загороднюк В., Шалашенко Г. Мова і дискурс: Ущербність «новоязу»: Філософія: світ людини. Курс лекцій. - Київ: Либідь, 2003.

[4] Колотілова Н.A. Інтерсуб'єктивний діалог в епоху постмодерну // Мультиверсум: Зб. наук. праць.-Вип. 23. - К.: Укр. центр дух. культури, 2001.

[5] Назарчук A.B. Этические проблемы глобализации сквозь призму дискурсивной этики // Этика глобализирующегося общества (тенденции и проблемы глобализации в социально-этической концепции К.-О. Апеля). - Киев, 2003.

[6] Саввіна Л.І. Деякі аспекти осмислення суспільства в комунікативній філософії Ю. Хабермаса // Мультиверсум: Філос. альманах. 2001. - Вип. 21.

[7] Фурс B.H. Модель коммуникативной рациональности в философии конца ХХ века // Весн. Беларус. ун-та. - Сер. 3. - 1995. № 2 .

[8] Хабермас Ю. Комунікативна дія і дискурс // Першоджерела комунікативної філософії. - К.: Либідь, 1996.

[9] Цаголова Р.С. Обоснование социологии коммуникации как научной дисциплины // Вестник Моск. ун-та, сер. 18. Социология и политология.- 1999. - № 4.

[10] Bogner $C$. Die Versöhnung der mit sich selbst zerfallenen Moderne: zum Verhältnis von Ethik und Gesellschaftstheorie bei J. Habermas / Christoph Bogner. - München: tuduv-Verl. - Ges., 1990.

[11] Habermas J. TkH, B. I. - Frankfurt am Main: Suhrkamp Verlag, 1981.

[12] Habermas J. Moralbewusstsein und kommunikatives Handeln. Frankfurt am Main: Suhrkamp Verlag, 1983.

[13] Habermas J. Wozu noch Philosophie? // Theorie und Praxis. Neu eingeleitete Auflage. - Frankfurt, 1998. 